\title{
On the Herd Behaviour of University Students Based on the Studies of Social Psychology
}

\section{Chunlin Li, Weixi Zeng*}

University of Electronic Science and Technology of China, Chengdu city of Sichuan Province, 610000, China

Keywords: herd behavior, group action, social psychology

Abstract. The herd behavior of university students is a common phenomenon of social psychology in university campus. This paper analyzes the concept and nature of university students' conformity behavior and summarizes the four common kinds of herd behavior, including learning herd behavior, occupation herd behavior, spending herd behavior and love herd behavior. The psychological reasons for the herd behavior of university students lie in the inheritance of traditional culture, incitement of mass media and the characteristics of university students. We should make efforts to learn the psychological reasons for the herd behavior to guide university students to think independent.

\section{Concept and nature of herd behaviour of university students}

Herd behaviour refers to the behaviour tendency of individuals to change their opinions under the pressure of the group, which is consistent with the majority of people. Herd behaviour is due to the pressure of group consistency, the individual seeks a way to resolve the conflict between themselves and groups, and enhance the sense of security means. As the university student is not mature in the psychology, the emotion is not stable, the social experience is not rich enough, the outlook on life has not been formed completely, therefore in the daily life and the study is easy to appear more conformity behaviour. The conformity behaviour of college students is that the college students are influenced by the society, the school, the class and other informal groups. There are three types of college students' conformity behaviour, positive, neutral and negative. For those who have positive significance of herd behaviour, as long as appropriate guidance, it is to promote the comprehensive development of college students and improve the quality of school education. Herd behaviour part of college students on college students' individual life, learning and habitual behaviour of the healthy development of college students has no obvious promoting effect, and no obvious hindering effect, herd behaviour can be summarized as neutral. The conformity behaviour of some college students is negative. It has a negative effect on the development of college students, and may even lead students astray. The negative conformity should be controlled and prohibited.

\section{Classification ofherd behaviour of university students}

It is very common for the college students to blindly participate in the classes and examinations in the study. They do not assess their own strength, do not consider their own interests, for students from without a purpose, the results of any help for their own learning, instead of wasting time. The loss often outweighs the gains. Students who learn bad grades, low activity, in the negative 
evaluation of teachers, parents and classmates long again, not only learning and living confidence hit, but also in others, learning ability, as long as they are consistent and will not make the wrong misunderstanding. Therefore, in order to less criticism, they only choose conformity. Even though he has sometimes seen the mistakes of other students, he will not dare to express themselves because of self-confidence, in the heart to retain their own ideas, but the surface of the herd. In college enrollment, students in class and dormitory are generally arranged at random, but after one semester there is a certain gap with the university life through year after year, all showed different levels, out of sync phenomenon. These are the typical performances of the learning herd behaviors.

For each college student, the employment occupies a very important position. In the social collective environment, many college students realize that they will face the severe employment situation. They expect second minor professional and study in the second degree and obtain all kinds of qualification certificates in the case of conditions. This kind of college students in the group learning and application of the common social function, generally recognized that in the study of the professional at the same time to broaden their horizons, as much as possible to master the relevant knowledge. They build on the knowledge structure of extensive and profound, adhere to the theory and practice of static and dynamic, personal interests and combined with social needs. College Students under the guidance of a good social atmosphere, the correct guidance of public opinion, the formation of these positive and progressive herd behaviour. Most college students expect to be able to work in the big cities in economically developed areas after graduation. Quite a number of college students to the public, state-owned units as the first goal of employment, a small number of willing to risk large private, joint venture employment. They just blindly follow the herd behaviour and choose the occupation with good benefits, leading to the loss of many job opportunities.

Herd consumption means that individuals are influenced by the behaviour of people in the outside world, and in their own perception, judgment, and understanding of the performance in line with public opinion or the majority of consumer behaviour. It is a common phenomenon in most individuals. However, it is easy to confuse it with the joneses. Comparison psychology refers to the different income groups, low-income consumers to high level of consumption as a reference to imitate. Generally speaking, as long as there is different social stratum, high income basic consumption for low-income consumption has demonstrative effect, low income inevitably to high income consumption in more or less degree of imitation, this kind of consumer behaviour is not healthy. Consumption should conformity, to do specific analysis. Conformity is a kind of will quality that people are opposed to independence. The strong independence of the people is poor, lack of initiative, easy to be implied, easy to accept the opinions of others and put it into practice. Herd behaviour also shows a more rational character in terms of the results of conformity. Under certain conditions, because there is not enough information or cannot collect accurate information, herd behaviour is difficult to avoid.

Campus love is very infectious. Some students think love or the pursuit of heterosexual friends prove their charm, ability. Some of the students will No one shows any interest in loneliness, loss and inferiority. College students have a strong need to be understood and respected by others, pay 
special attention to group evaluation, and be sensitive to public opinion. This is also one of the reasons why college students love the herd mentality so high. In the early days of the social needs of the people, mainly outside the family to seek emotional attribution of the object, including the establishment of friendship with same-sex friends, and heterosexual friends love. At the same time, college students' psychology and physiology are not mature, lack of experience in emotion. By the way, in order to avoid loneliness, conform to the flow, love is on the agenda. Man is a social animal, college students is a member of the university campus, college students to adapt to the life of the university campus to the desired direction of development. Love is the form to fully integrate into university life. It is the same as most of the people fall in love to make heterosexual friends in the university campus.

\section{Reasons for herd behaviour of university students based on social psychology}

Since the formation of the Chinese nation, most of them are governed by the feudal system, thus forming a set of inherent conservative, compliance, the overall mentality. China has a stronger sense of group organization, because the Chinese tradition is to emphasize the collective, to light the individual, to weigh the theory, to light the practice, to weigh the system and to the light. This tradition makes Chinese people can not hesitate to contribute to the collective, but also more prone to blindly follow the collective behavior. It has gradually formed the group norms, group norm refers to the individual members in the group activities must abide by the rules, including the group value in a broad sense, the group members are the standard for judging the quality of a non. The maintenance of group norms, generally rely on a set of default tend to spiritual rewards and punishment mechanism. The reward and punishment mechanism can be an individual, an organization or a society. This is the result of the influence of power on public education. In order to avoid the choice of personal consciousness will punish compliance, compliance is a kind of on the surface of the herd, the general said the confession to them. You will be punished if you don't obey. When the pressure of authority, the public has to comply with the herd behavior. Until today, people have become accustomed to listen to the instructions of the leadership, so that there is a blind faith in the various levels. The idea is to make them form the moral concept of group first. A study of the localization of Chinese youth values leads to the conclusion that. The value choice of Chinese youth is always closely connected with other people and the specific situation.

The media is like a national speaker. The media can spread the news, can reveal the facts and truth, but also can create guide public opinion. In today's era of peace and development, the power of media has become one of the most important weapons in various countries and on the competition between each other. To a large extent, the media is not only to guide people's behavior, and even determine the behavior of people. The media has a tendency to choose the report, he will show us another world in the form of text images, that is, to build a picture in our minds. Due to the recent rise of the media, so that the proliferation of information. With the government of serious sensitive information blockade, resulting in lower openness to the official public half believe and half doubt, distrust of experts' rhetoric, also led to a certain degree of dependence on the public media and hearsay, which appeared in the media guide some blind phenomenon. Encourage 
positive, healthy and lively atmosphere. The herd mentality produced in this group atmosphere is generally positive. It tends to make the individual positive, the collective sense of honor of the group members. The unwritten normative force, will enhance the tendency of the individual, leading to a positive effect. Under certain conditions, because there is not enough information or cannot collect accurate information, herd behavior is difficult to avoid. It is not a problem for individuals to choose strategies by imitating the behavior of others, and sometimes imitation strategies can effectively avoid risks and make progress. Educational administrators can set an example or a typical character, and vigorously promote, which has a very significant effect in the group of students who have a strong tendency to conform. The media to make use of the form of the list, to stimulate the public's eye, to guide the public consumption trends. The complex social reality erodes the bottom line of the value system. The values and norms of behavior in various traditional deconstruction and reconstruction, the value concept and the new code of conduct clearly still in the process of implementation, there are many new problems, parents and families and can't cope with. It is not difficult to find that the media recommended the top three books, movies, brands are generally favored by the public. Once the use of media power reported they would fall on someone's wickedness he rebuked, abusive and hate may not be alive. With the development of the event to the white hot, the public has no longer explore how the case, but directly for their individual, and even the whole family together, vent like criticism. Finally, the public may have forgotten what they are doing, but with the will of the majority.

University students are in the period of study, basically living in the university campus. This group belongs to the peer group, and plays a very important role in the socialization of the individual. The development of a person depends on the development of all others who are directly or indirectly connected with him. Students living in very similar relatively closed peer groups, pressure groups and groups in the omnipresent interactive context, people will often give up some ideas, values and their behavior and take consistent with most people's behavior. When young people are affected by the contradiction between the adult and the same age partners, they often choose the standard of their peers, which is mainly caused by the special stage of the psychological development of college students. Improve individual cognitive ability, enhance self-confidence. The results show that the individual cognitive ability and self-confidence are in inverse proportion to the herd behavior, but the tendency of the individual is often due to the lack of knowledge in certain aspects, the lack of self-confidence and so on. Try to avoid large group meetings in emergency situations. According to social psychology, there is a positive relationship between group size and conformity rate. In a state of emergency, the larger the size of the group, the more likely to be infected with each other, and the emotional imitation, the individual will often make irrational behavior. Adverse psychological phenomenon should pay attention to correct. The consensus of opinion will increase the conformity rate of the members. But if someone is able to adhere to a different opinion in the case of consensus, it will reduce the blind herd. In the spread of undesirable psychological phenomena, we should encourage and support the number of people who may have different views, in order to reduce the psychological conformity rate. The students in the psychology because of the lack of social experience, knowledge, thinking level needs to be 
improved, the outlook on life, value and world outlook has not yet fully formed, causing them to self-development to grasp a kind of helpless, sometimes even deny the reliability of human rationality. Psychologist Erickson believes that in the early days of the social needs of the people, mainly in the family to seek emotional attribution between the object, including the establishment of friendship with same-sex friends, and heterosexual friends love. University students have a strong need to be understood and respected by others. They pay special attention to group evaluation and be sensitive to public opinion.

\section{Conclusion}

The herd psychology and behaviour of university students not only may have positive effects, but also may have negative effects, or no obvious positive and negative effects. We should give full play to the positive role of herd behaviour, enhance the collective consciousness of college students and cultivate the good style of class. At the same time, we should avoid the negative effect of the herd behaviour, eliminate the negative effects of college students' dependence. In short, we should develop college students' ability of independent thinking to promote the model of the behaviour originates from their own judgment.

\section{References}

[1]Yao Guirong, On the Social Psychology Analysis Based on Conformity Behavior in Great Leap Forward Movement, Journal of Xiangtan University (Philosophy and Social Sciences), 36(4), pp. 134-138, pp. 70-73, 2012.

[2] Zhao Gaohui, Cheng Pei, Characteristics, Motive and Response to Group Events in Colleges and Universities - Integration Analysis Based on Collective Action Theory, Journal of Chongqing Technology and Business University (Social Sciences Edition), 30(5), pp.100-105, 2013

[3]Zhang Boying, Research on the college students herd behavior basedon FAHP and fuzzy evaluation, Journal of Chongqing University of Arts and Sciences, 35(2), pp. 46-50, 2016.

[4] Jiang Juanli, On the Group Action of Chinese College Students in Tourism, Journal of Yunnan Nationalities University, 25(2), pp. 70-73, 2008. 